\title{
From idea to product - participation of users in the development process of a multimedia platform for parental involvement in kindergarten ${ }^{1}$
}

\author{
Dionisia Laranjeiro ${ }^{1 \text { [0000-0003-3347-7967] }}$, Maria João Antunes ${ }^{2[0000-0002-7819-4103]}$ and Paula \\ Santos ${ }^{1}$ [0000-0001-7898-8731] \\ ${ }^{1}$ CIDTFF, Dep. Education and Psychology, University of Aveiro, Aveiro, Portugal \\ ${ }^{2}$ CIC.Digital/Digimedia, Dep. Communication and Arts, Univ. of Aveiro, Aveiro, Portugal \\ dionisia.mendonca@ua.pt, mariajoao@ua.pt, psantos@ua.pt
}

\begin{abstract}
Parental involvement in kindergarten has been pointed out as an important factor in cognitive development, child behavior and school adaptation. In kindergarten, parents can get involved in various ways. Web technologies can facilitate two types of parental involvement: communication with the early childhood educator, to learn more about child's learning process in kindergarten, and home-based educational activities, using digital educational content. In this sense, the research team set up a design research, aimed to develop a multimedia platform that promotes communication and resource sharing among educators, parents and children, to facilitate parental involvement in learning. This article presents the development of the platform, from the preliminary studies to the evaluation of the functional prototype, with the participation of parents and educators in all phases of the development process.
\end{abstract}

Keywords: Parental involvement, Multimedia platform, Prototype development, Learning process in kindergarten.

\section{Introduction}

Parental involvement (PI) is a very broad issue that implies the participation of parents in children's formal learning process, taking part in school-related activities [1]. Studies suggest that PI is a multidimensional construct and different types of PI may provide diverse results. Epstein [2] developed a theory and framework with six types of PI: parenting (e.g. parents offer a supportive environment and conditions to learn), communication (e.g. exchange information with school), volunteering (e.g. fundraising, helping in classroom), learning at home (e.g. help with homework, develop educational activities), decision-making (parents' participation in school decisions), and collaboration with the community. This framework is largely accepted and used by schools to promote family-school partnerships. Hoover-Dempsey and Sandler [3] present another theoretical model for PI, focused on "why" and "how" parents get involved in their

\footnotetext{
${ }^{1}$ From the article presented at the $9^{\text {th }}$ International Conference on Computer Supported Education[43]
} 
children's learning. They also consider involvement activities at home, involvement activities at school, parent/teacher/school communications, but they add another form of involvement, which is values, goals, expectations and aspirations parents communicate to their children, thus influencing attitudes and behaviors toward school. In Early Childhood Education (ECE), the Harvard Family Research Project distinguishes three processes of PI related to young children's outcomes: parenting, consisting of attitudes, values and practices in education (including parent-child relationship and child-centered activities); home-school relationships, comprehending formal and informal connections between parents and kindergarten (e.g. communication with the educator about their children's achievements and behavior, participation in the classroom, volunteer to solve a problem or organise an event); responsibility for learning, that refers to activities parents can do with children to promote learning skills (e.g. reading or cooking with the child, visiting museums or libraries, talking with the child about school) [4].

There are several studies that recognize the importance of PI for the success of children's learning, pointing it as an important factor in the development of skills and the results achieved $[5,6]$. It's associated with higher grades and test scores, better attendance and more homework done, better grades and fewer placements in special education [7]. PI has a significant effect on child's adaptation to school and success in learning, regardless of other factors, such as social class [8]. Involvement at home plays an important role in student achievement and positive attitudes toward school [9]. Expectations that parents transmit to their children about what they academically aspire to them have strong influence on their success [10]. Also, communication between parents and children is a key factor to help them succeed in study. With regard to preschool children, PI also has an impact on general development, cognitive development and school readiness [11]. Positive relationships between educators and parents have an effect on children's social skills [12]. Some studies have found a positive relationship between PI in kindergarten and the performance of children in reading and mathematics [13]. An essential element for PI is school-family communication. Effective communication is associated with academic success [14]. When parents communicate constructively with teachers and participate in school activities, they have a greater understanding of what their children should learn and how they can improve their formal education at home [15]. Parent collaboration in school community is also related to better results and better student behavior [5]. Success at a later stage of life, particularly in employment, is established in the preschool years, which are the basis for acquiring study and work skills. This requires strong partnerships between agencies, families and children [16].

The importance of PI is recognized in governmental guidelines for ECE in several countries [17]. The No Child Left Behind Act (NCLB), implemented in USA Schools, recognizes that PI is part of children's academic success and should be integrated into school curricula [18]. Other countries implemented programs valuing parent's role in children's education, such as "Children's Plan" in UK and the "Schooling Strategy" in New Zealand" [19]. In Portugal, the Ministry of Education published the "Curriculum Guidelines for Pre-school education", an official document with a set of principles for kindergarten educators. Throughout the document, there are numerous references to PI, referring the need to establish bilateral and positive communication, promote good relationships and encourage the participation of families in the educa- 
tional process [20]. However, PI has logistical, emotional or cultural constraints. Barriers to PI can be categorized in four areas: family factors, child factors, teacher-parent factors and society factors [19]. Family factors include parent's beliefs about PI (the role they think they should have in their child's education), parent's perception of invitations from school (if the school is welcoming to PI), parent's life context (work, family, health, schedules); class, ethnicity and gender. Factors related to the child are: age (PI decreases as children grow up), learning difficulties/disabilities as well as gifts and talents (sometimes bring disagreement between parents and school, parents lose confidence and reduce PI), behavioral problems (possibly make parents reluctant to go to school). Parent-teacher factors may be different goals and attitudes about PI, having major repercussion in the way PI is perceived and implemented. Society factors include historical (school culture based on formality and inflexibility), demographical (changes in family structure), political (lack of legislation about PI) and economic factors (little money assigned to PI initiatives). The report Learning in families [21] presents results of a survey to parents of pre-school and elementary school children, identifying barriers to PI in ECE and indicating lack of time as the most important. Other barriers encountered were costs associated to transportation or babysitting, and difficulties in communicating with teachers $[14,21]$. A study conducted at 1205 kindergartens, to ascertain PI over the years, has shown that the quality of interaction between parents and educators decreases, although participation in home-based activities is consistent over time. It suggests that activities requiring physical presence in school are more difficult to maintain [22].

Today, we witness the use of technology in everyday life, for a variety of purposes, from work to entertainment, communication and personal organization. Technological tools, such as websites, social networks, blogs or e-mail, create new channels of communication and information sharing, and can improve the relationship between educators and parents. The importance of technology for PI in learning is mentioned by several authors [23-25].

Some studies corroborate that technology represents an opportunity for increasing communication between parents and schools, as well as PI. In USA, a large-scale study intended to examine the usage and benefits of Internet-based communication between parents and school. The study involved 14.387 teenagers, $88 \%$ of participant's parents and $99 \%$ of their school administrators. Parents completed questionnaires about parental involvement and Internet-based family-school communication. School administrators' questionnaire asked whether teachers used Internet to communicate with parents. Students completed achievement tests in $10^{\text {th }}$ and $12^{\text {th }}$ grades. Results show that Internet-based family-school communication is associated with higher achievement and higher educational expectations, and students from all backgrounds benefit equally from Internet-based family-school communication. These findings suggest that Internet is an opportunity for promoting family-school communication [24]. In a case study involving two elementary schools, students, teachers and parents, L. Grant [23] found that there was a discontinuity between what children learn at home with parents, and what they learn in schools. Parents, teachers and children considered that the use of technologies for school-family communication could play a positive role by making communication more direct and timely. Blanchard [26] examined four projects of introduction of technologies in schools, reaching conclusions in the area of PI and school- 
family connection. She pointed out some advantages. Technology can help establish a two-way connection by making parents aware of the academic reality of the school and teachers' can better understand families' responsibilities. Technological tools can promote conversations within families on school issues. Technology can involve families difficult to reach. Technology can extend learning opportunities from school to home, for example, guiding parents to act as instructors and help homework. The use of technology also motivates children to learn. Technology can help reduce costs involved in educating children. Ellen Lunts [14] describes how different technologies can be used in PI. One suggested is e-mail, because the teacher can easily reach all parents, who can respond at a convenient time. Web sites function as information broadcasters and link to families and communities, informing about the curricula and course objectives. A classroom website can complement instruction and communication with parents, display students' projects, assign homework and suggest tips for parents to help. Chat rooms/videoconferencing are an opportunity for interaction in real time, between parents and the teachers. Olmsted study's [25] purpose was to determine whether technologies facilitate parent-teacher communication and parent involvement. Data were collected through surveys and semi-structured focus group interviews. She concludes that online textbooks, links to educational websites and teacher websites provide resources to parents to engage in their children's learning at home. Blogs, wikis, and e-mail provide two-way communication between school and home. Voice-calling systems keep parents contactable. Institutional websites spread important news and events about the school. Teachers' websites provide parents with homework assignments and class news. Parent portals allow parents to access students' courses, homework assignments, grades, attendance, and allow parents to directly communicate with teachers. Text messaging, instant messaging and social networks can also be used to keep parents informed about school. Virtual Learning Environment (VLE) software provides group discussion, chat, scheduling and collaboration tools, that can be used for PI and reduce barriers such as different schedules of teachers and parents [27].

Horizon Report Europe [28], which examines trends and challenges of technology in education, point to social networks as a fast trend to accelerate the adoption of technologies in schools, as they provide dialogue between students, teachers, parents and institutions, helping parents to stay informed and giving feedback to teachers. On the other hand, children grow up well acquainted with technologies such as computers, Internet, videogames, tablets and mobile phones, using them to play, learn and communicate. Digital educational resources can be part of learning activities promoted by parents or educators, and can be shared between them, using online tools.

\section{$2 \quad$ Methodology}

Given the relevance of the theme and verifying the existence of specific needs at this target audience, the research team decided to develop and evaluate a multimedia platform, using design research methodology, to answer the question: what are the functionalities, contents and dynamics that a multimedia platform must have to promote PI in learning of children attending kindergarten? 
The term design research covers a group of research methodologies based on design and development, with some variations [29]. So, it's pertinent to highlight some specific characteristics of this methodology: it includes activities of analysis, design of educational prototype, evaluation and revision [30]; scientific knowledge influences development, which is then tested in the field, bringing empirical data to improve the product and validate knowledge; the development process is interactive and iterative, as it reaches a satisfactory approximation of the ideal intervention; it allows to exploit the potential of ICT, in order to solve a real problem in education [31]; It is based on rigorous and reflective research to build knowledge and principles that can guide future developments and studies [32]; The user is involved in the entire process, from preliminary studies to evaluation, in order to obtain a higher quality intervention [33]. This type of research can bring specific knowledge to a context, but be transferable and relevant to other learning environments [34]. This research is being carried out by the authors (research team from the University of Aveiro), in collaboration with the multimedia company Criamagin ${ }^{\circledR}$ (development team), four educators and 84 parents of three kindergartens in Aveiro (target audience). In this way, the target audience is integrated into the project in all phases: collaborating in the preliminary study, that will help to define the functional specifications of the platform; using the prototype and participating in tests and improvements; contributing to a final study on the impact of the platform on PI in the learning process of children attending the involved kindergartens.

Several authors present models for the operationalization of design research. Although the models vary in detail, they have similarities, synthesized by Plomp [35] in three stages: preliminary studies, development and evaluation. For this study, the model was adapted as follows: Stage I - Preliminary studies, consisting of literature review and search for state-of-art platforms, characterization of participants, survey the needs of educators and parents. Stage II - Iterative development of the platform, consisting of cycles of analysis, design, evaluation and revision of the prototype, until reaching the final product, involving the target audience in all process. Three development cycles are planned: First cycle - functional specifications, paper prototype and usability tests; Second cycle - functional prototype, pilot implementation in kindergartens and use by educators and parents, for tests and evaluation; Third cycle - final product, use in kindergartens. Stage III - Final evaluation of the impact of the product on PI in children's learning. This moment helps to verify the success of the product, i.e., to ascertain the practical results and contributions to the theory, as well as, suggestions for future studies.

Design research uses mixed methods to collect data, analyze and refine the intervention [36]. Thus, a combination of different forms of data collection is used in this study, such as inquiries (interviews, focus groups and questionnaires), observation, usability tests, e-mailing and meetings with the users, access to platform content and statistical data. Content analysis and descriptive statistical analysis were used to analyze data. Next sections present the results of preliminary studies, the first cycle of development and the beginning of the second cycle of development. 


\section{$3 \quad$ Preliminary studies}

This research involves four classrooms of three kindergartens, with the participation of four educators and 84 parents. Preliminary studies started with a questionnaire to parents (responses $=59$ ) and interviews to the four educators to include both perspectives and needs in a platform that should improve communication and promote PI in learning. Also, the search for existing platforms helped to identify their main features and to understand market trends. A literature review was done to find out research about PI with technological tools, to predict good practices and learn from projects already implemented.

The questionnaire to parents was divided into three parts: The first one was aimed at characterizing the parents' technological affinity; at the second part, it was intended to identify the characteristics a platform should have in order to promote their involvement in their children's learning process - most important features and contents, dynamics that must be provided, presentation, update frequency, access permissions, devices used; the third part focused on the collection of personal data, needed for contextualizing the responses.

Results of parent's questionnaires showed that they have access to technology (Internet, computer and mobile phone) and most parents use it every day. They have reasonable to good knowledge about different Internet services (e-mail, social networks, web search). Most parents perform technological activities with their children (filming, show photos, playing games and apps). Their children access technology at home, being the tablet their preferred device. Parents value some features: news and events calendar, photo and videos gallery of children's projects and private messaging with the educator. The greater advantage of the platform is to access updated information on the work carried out at kindergarten. A general concern is the protection of personal information, in particular, sharing photos where children are identified. For the assessment of educators' needs, semi-structured interviews with the four educators participating in the research were carried out, to find out how they use technology in activities with children, to communicate with parents, and to understand educators' perceptions about the use of the platform - advantages and disadvantages, the devices to use, frequency of use, contents to share, tools and dynamics that the platform should contemplate. Since they will play the main role in the dynamization of the platform, it was essential to understand what could lead to its adhesion and use. Results of interviews with educators indicate that the platform must gather official information of kindergarten and direct contacts of parents. Also, it should integrate specific areas, such as child/group history, activities being developed, suggestions of activities to do with children and links to educational resources. The biggest advantages are celerity and automation of communication; promotion of parent's feedback; separation of professional contact from personal social networks. The constraints are lack of time for maintenance and parent's fear about privacy issues. Educators use the computer and the mobile phone for different purposes, and associate the execution of long tasks to the computer and immediate tasks to the phone, reason why the platform must be adaptable to different devices, to 
have a more effective use. There were few allusions to the use of the platform by children and there is no mention of the impact or benefit that a platform for PI can bring to children's learning, which seems to reveal that the educators are looking for a tool focused on communication and information sharing among adults.

Another preliminary study was the web-search for state-of-art platforms, with the objective of knowing the variety of platforms for PI in the national and international market, identifying the features they offer, innovations, trends and good practices, as well as weaknesses that can be suppressed. Search was done using Google, blogs, digital magazines and websites of technologies in education, and resulted in a set of sites that offer platforms, reviews, experts opinions and links for download.

This study revealed the existence of a considerable set of platforms that facilitate communication between schools and parents, such as Classdojo, Classmessenger, SimplyCircle, FreshGrade, Edmodo, ParentSquare, MyChild, Weduc ${ }^{2}$. The most common features are: private groups, with the possibility of associating teachers, students and parents, individual/group messaging; image gallery; and events calendar. Some platforms have social network components (e.g. like, share, comment), others have Virtual Learning Environment components (e.g. creation of tasks, students' monitoring). Two platforms allow the customization by the institution (e.g. logo, colors). There was only one platform specifically developed for ECE, and it focus on disseminating information (events that happened or that are planned), but lack the provision of strategies or suggestions that parents can explore at home, contributing more actively to their child's learning.

Literature review presents some research projects which promoted PI in kindergarten through technological tools. Some results are: active participation and higher feedback from parents; awareness about the work developed in kindergarten; improvement of relationships between parents and educators; parents' ability to extend home learning based on the information shared; reading comments with children contributed to collaborative and constructive learning [37-40]. A detailed presentation of the preliminary studies, methodological decisions and a critical discussion of the results found at this stage, can be consulted in Laranjeiro, Antunes and Santos [41].

\section{First cycle of development}

\subsection{Conceptual Structure}

Based on the contributions of the preliminary studies, the II Stage of research started. In the first cycle of development, the functional specifications of the platform were defined. These resulted in a paper prototype, subjected to usability tests for formative evaluation.

\footnotetext{
2 Platforms Webpages: www.classdojo.com, www.classmessenger.com, www.remind.com, www.simplycircle.com, www.freshgrade.com, www.edmodo.com, www.parentsquare.com, www.mychild.pt, www.weduc.com
} 
Functional specifications are detailed descriptions of the functionalities that will be included in the platform, to meet the needs of the users and the objectives of the product [42]. This is an essential document for teamwork as it is a starting point for a joint understanding of the product. Until the specifications are written, there are many development possibilities, derived from brainstorming sessions, team opinions and user surveys. Functional specifications must clearly limit the scope of the project, defining what will be done and what will not be done, and set priorities (most important features first) and responsibilities in development (who must deliver what). Functional specifications were written following three principles: specific, objective and positive description (say what the system should do, instead of focusing on what should not happen), avoiding misinterpretation [42]. The definition of functional specifications allowed the organization of the conceptual structure of the platform, that is presented in an architecture diagram (Figure 1), a flowchart showing the organization and interconnection of different areas [42]. The unit of the diagram is the node, which corresponds to a sort of information. The structure is hierarchical, composed of categories and subcategories, forming a navigation that is consistent and easy to learn by the user. Starting from the homepage, it is divided into four main nodes. Within each node, specific contents and functionalities are presented. The diagram shows the nomenclature used in buttons and menus.

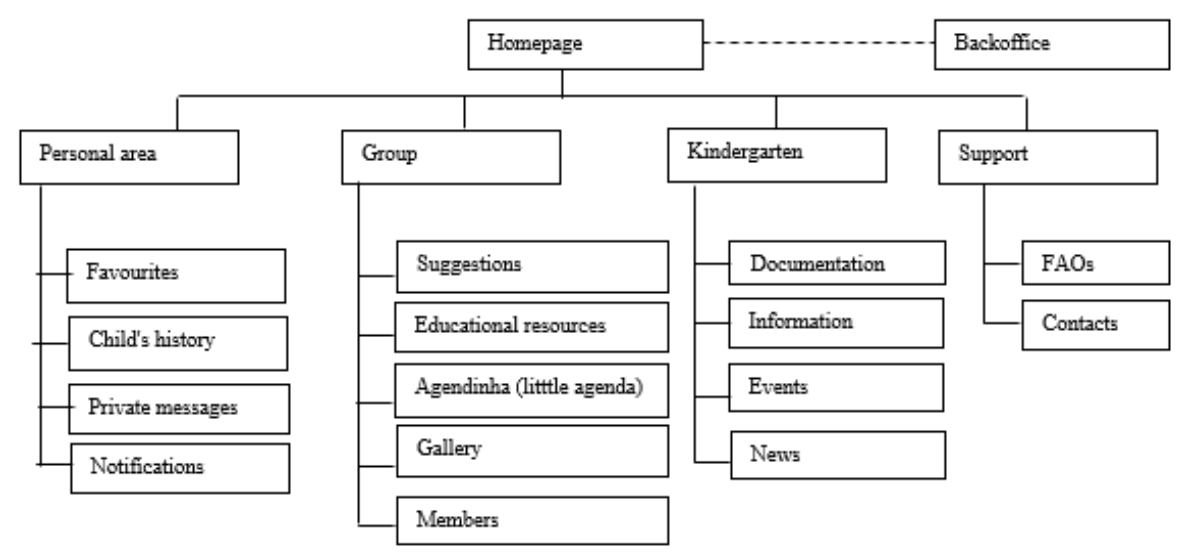

Fig. 1. Architecture diagram [43]

\subsection{Functional specifications}

The platform is divided into four areas, defined by the type of information, level of privacy and access permissions. In the personal area, there are functionalities and contents available to each user, individually and privately - access to child's history, private messages service, favorites and notifications. In the group area, content is published and shared by all members of the group, educator and parents - suggestions, educational resources, agendinha, gallery, members. In the kindergarten area, the educator provides institutional information to parents - documentation, information, events 
and news. The support is an area where users can contact the development and research team, as well as find more information about the project. The functional specifications are presented below, briefly, for the understanding of each functionality, layout and navigation of the platform.

General specifications - the left side menu appears in all pages, giving access to three areas (personal, group, kindergarten). Each area contains submenu buttons, using the nomenclature defined in the architecture diagram. The logo of the project is placed in the header. Group name and user's photo must always be present, in an upper area of the site. In the central block, below the heading, is placed the writing area, where users can write posts. Below the writing area, posts of group members appear in chronological order. Group members can comment a post. On the right-side menu, there are news of the institution, calendar of events and support area.

Writing area - in all pages there is a writing area, where users can write posts, to share contents with other group members. Users can choose where they want to publish the post, selecting the corresponding tab - messages, agendinha, activities, educational resources. By default, the 'messages' tab is selected. Messages composed in this tab will appear at homepage. If users want to choose another area to write, they must change the tab. If they choose 'Educational Resources' tab, they can insert links to web pages, apps, educational games and other resources that will appear in Educational Resources Area. In each post, they must include title, link, description (required) and images (optional). If they choose the 'Activities' tab, they will insert content in the 'Suggestions' area. Here, they can choose typology: Books and stories; Songs, Handcrafts, Games and playtime, Outdoors, Other. Each contribution consists of title and description (required), link and images (optional). If they choose Agendinha tab, they can insert events, using subcategories - exhibitions, cinema, theatre, music and other shows. Each contribution is composed by title and description (required), link, images, date (optional).

Homepage - at homepage, all contents published appear in chronological order, regardless of the area where they are associated. Thus, there is a chronological presentation of all posts, but at the same time, there is an organization by type: Agendinha, suggestions, educational resources.

Next, the descriptions of the main features are presented. In the group area, there are the following nodes: Gallery, Educational Resources, Suggestions, Agendinha, Members.

Gallery - area where parents and educators can share photos, videos and audio files. Possibility of creating albums within the gallery, associating name, description and date, for organization of contents. Upload of contents into an album and possibility of editing description. Chronological listing of albums and contents. Ability to comment and reply to comments about a content.

Educational resources - area where users can see the list of links inserted by group members. The list appears divided by typologies (websites, apps, games, others). Within each typology, links appear from the most recent to the oldest. Possibility for each member to mark a link as favorite. Ability to comment and answer to comments on each item. 
$\underline{\text { Suggestions }}$ - area where users can see all suggestions of activities inserted by group members. The list appears divided by typologies: Books and stories; Songs, Handicrafts, Games and playtime, Outdoors, Other. Activities appear from the most recent to the oldest. Possibility for each member to mark an activity as favorite. Ability to comment and answer to comments on each content.

Agendinha - area where users can see all events inserted by group members. The list appears divided by typologies: exhibitions, cinema, theatre, music and other shows. Events appear from the most recent to the oldest. Possibility for each member to mark an event as favorite. Ability to comment and answer to comments on each item.

Members - area presenting the list of group members, with photograph and name. Photos connect to the public profile page, which displays personal information - photography, name, publications on the platform and direct connection to private messaging.

In the kindergarten area, there are the following nodes: Events, News, Information and Documentation.

Events - kindergarten calendar, where educators can highlight activities already done or to be carried out in the future, for example, Mother's Day, Christmas. Each contribution consists of a title, a description, date (required) and images (optional). This functionality is visible to all members, but only available for editing by educators, who have permissions to insert, edit and delete events.

News - news are composed of title, text (required) and image (optional). They serve to communicate official information from the kindergarten. News are listed from the most recent to the oldest. This functionality is visible to all members, but only available for editing by educators.

Information - area where educators can upload temporary files (.pdf or .jpg) to parents, such as weekly menu and weekly planning. Possibility of associating title and description to the file. List from the most recent to the oldest. This functionality is visible to all members, but only available for editing by educators.

Documentation - area where educators can upload files (.pdf or .jpg) to parents, such as regulations, school calendar, pedagogical plan, other. Possibility of associating title and description to the file. List from the most recent to the oldest. This functionality is visible to all members, but only available for editing by educators.

In the personal area, there are the following nodes: Events, News, Information and Documentation.

Private Messages - area where private messages can be read and written. Ability to create message and choose the recipients from the list of group members - educator, member, several members or the whole group. Ability to respond to a message.

Favorites - accessing this area, users can view all the posts they saved as favorites, listed and divided by categories - agendinha, educational resources, suggestions.

Notifications - users can receive notifications by e-mail. They can customize notifications by frequency - choosing to receive a daily or weekly summary; members - receiving notifications from the educator, a specific member or all members; and areas choosing to receive notifications about events, educational resources, suggestions or messages. In the personal area, users can see and delete notifications. Unread notifications are written in bold, to be distinguished from the others.

Child's History - in this private area, parents have access to information sent by the educator about their child - images, files (e.g., pdf document with annual evaluation), 
or text messages. The information is stored in chronological order, constituting a portfolio or history of the child, related to his/her development and achievements in kindergarten. When accessing the child's history area, the educator has a drop-down menu to choose the parent and, after this step, share private information about the child.

In addition to the personal area, group area and kindergarten area, the support area offers information to users, providing explanations about the portal, how it works, what functionalities are available, how to participate, conditions of use. It also has a form to contact the development team, addressing suggestions, debug and help.

For managing information, users and accesses to the platform, it is planned to develop a Backoffice. In addition to the profile of educator and the profile of parent, there is a third profile, the administrator's, that belongs to the development team of Criamagin, responsible for managing the platform. The administrator has got access to the Backoffice, to monitor platform data, access usage statistics and manage rooms and users. The administrator creates access to the members of kindergarten, which means creating groups, registering users with e-mails (previously provided by the kindergarten), and associating users to a created group. Users receive an e-mail confirming registration, with instructions to enter and start using the platform.

\subsection{Paper Prototype and Usability tests}

With the definition of the functional specifications and the architecture diagram, a paper prototype of the platform was elaborated (Figure 2), to test the usability and the overall design with the user, at an initial phase of development. Usability is formally defined in standard ISO 9241, as the ability of a product to be used with effectiveness, efficiency and satisfaction by specific users to achieve their objectives in a given context [44]. It is a quality attribute that measures whether the interface is easy to learn and use, whether the features are easy to remember, the type and number of user errors, and speed of task execution [45]. 


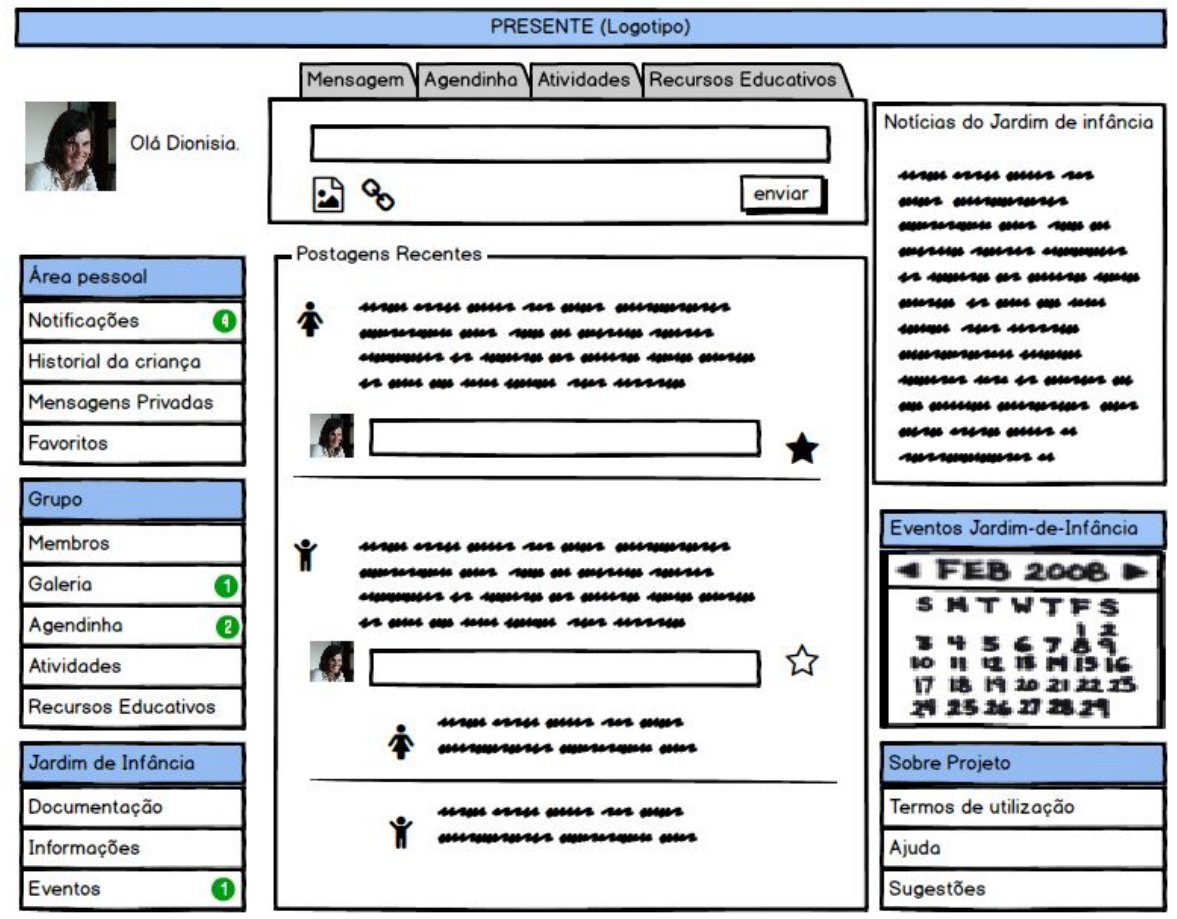

Fig. 2. Paper Prototype

A paper prototype is a recommended technique for making usability studies, in the beginning of the development, because its implementation is fast and economic. It allows the team to gather data about usability, at a very early stage of a project, and to improve the user experience. At this stage, it is still possible to change the approach to the problem, change the set of resources specified for development, and even change the interface architecture. These changes are no longer feasible in terms of costs and deadlines when the product is tested at a later stage of development [46].

At this global design definition phase, the topics to be evaluated with the user are Relevance (to verify if there is the need for the platform - content validity), Consistency (to check it's properly planned or structured - construct validity) and Practicality (to check if users expect to use the product in the context for which it was created) [33]. This constitutes a formative evaluation that is a systematical procedure, including planning tests, data collection and analysis, and report). The study of usability in the global design phase doesn't focus on graphic or layout, but test general understanding, navigation, concepts, buttons and menus nomenclature, contents associated to each area, choices to display information on each page, identification of missing features and resources [46]. For these tests, there is no need to have all functionalities implemented, but an horizontal representation, a first level that presents the features and allows the users to perform/simulate tasks [47]. A balanced usability test can be performed with five potential users. Five users discover $80 \%$ of the problems, including in this percentage the biggest problems. The fifth user typically observes the same results and does 
not add much new information. In case there are different categories of users, for example, teachers and students, it is advisable to test with three potential users of each group [48].

The paper prototype was created to be tested with users. It was necessary to simulate the main areas of the platform and create a fictional room, with members of both profiles (educators and parents), to better understand the interactivity, navigability, dynamics and contents generated in the platform.

Usability tests planning. The test plan is based on the recommendations of Rubin and Chisnell [47], and describes what will be done during the test, discriminating objectives, participants and procedures. Usability test objectives are: to probe the relevance, consistency and practicality expected of the use of the product, by two groups of users (parents and educators); to understand whether both groups of users can use the product equally well; to identify obstacles to use. Tests followed a common set of procedures, starting with the presentation of the study to the participant, noting that it's not the user that is being tested, but the product, and that his/her participation is important. Then, the participant filled out a small questionnaire about knowledge and experience with Internet communication tools. The usability test had two parts. First, a "walk through" [49] the paper screens, which means that the participant describes the screen, areas and functionalities. After the initial description, the prototype was evaluated based on the accomplishment of tasks proposed by the moderator, simulating the use of the platform. According to the question asked, participants pointed out with the finger and explained the procedure to accomplish the task. As they finished the task, they moved forward, changing the page of the prototype. Researchers encourage the use of the "Think aloud" protocol [50] by the participant, to facilitate researcher's annotations. Tests ended with an interview related to attitudes regarding the use of the platform, to know the opinion and perceive the interest and expectation of users.

Eight individual tests were carried out with four educators and four parents, representing both groups of the platform users. The instruments were pre-tested with a parent from another kindergarten.

With these tests, researchers intended to collect two types of data: performance data, that includes errors, omissions and completed tasks, understanding of the structure and navigation; preference data, in particular, the ease of use and learning, nomenclature, perceived utility, expectations. The results of the paper prototype usability tests are presented below, suggesting changes and improvements to implement in the functional prototype.

Usability tests results. The usability assessment was done with four educators (E1 to E4) and four parents (P1 to P4). According to the data collected through the questionnaire, all of them use Internet services every day, but have different levels of participation in social networks, from observation (e.g., P2 and P3 only read posts) to full social interaction (e.g., P4 and E4 read/write/answer posts, share images/videos; belong to Groups; use instant messaging). These profiles represent most of the parents involved in the project and, at the same time, reveal a level of technological affinity needed to understand, test and critically evaluate the platform. 
Initial considerations. After ended the questionnaire, participants described the main screen, on paper, pointing out the defined areas, giving suggestions and expressing doubts. This part of the test served to verify the general understanding of the platform and hear the first opinions of the eight participants. All participants understood the general layout, identifying the menu area, the writing area, and the body of the site, where users' posts appear, as well as the division of the menu into three sub-levels (personal, group and kindergarten). Some considerations were retained for possible implementation in the second cycle of development. E1 thinks that the tabs above the writing area are confusing, as well as the use of the word 'Messages'. She was unsure if it was related to private messages or messages to the homepage. She suggested to put the writing area of each section only in that section, that is, if the user is at the homepage, his posts appear only there. The tabs were not understood by P2, who described it as buttons to change pages. E3 asked if 'Child's History' is only accessible to the child's parents, showing concern about privacy. She also suggested that parents could share with the educator what their children do at home, in this private area. P3 noticed that the posts did not have date and time details. Three parents asked about the possibility of blocking members.

Results of tests with tasks list. After the initial description, the moderator applied a tasks list, which users performed sequentially, simulating the action on the paper prototype, pointing the finger and changing the page to move forward.

Table 1 presents the tasks questions associated to functionality and the participants who could successfully complete the task (x). For those who did not understand the task or performed it with error, that space remains in blank. Visually, the table gives an overview of the functionalities best understood and the ones that caused major errors.

Table 1. Tasks and performance of the users[43]

\begin{tabular}{|c|c|c|c|c|c|c|c|c|c|}
\hline Task & Functionality & E1 & E2 & E3 & E4 & $\mathrm{P} 1$ & $\mathrm{P} 2$ & P3 & $\mathrm{P} 4$ \\
\hline $\begin{array}{l}1 \text { - Who is the user who owns this } \\
\text { page? }\end{array}$ & Profile & $\mathrm{x}$ & & $\mathrm{x}$ & & $\mathrm{x}$ & $\mathrm{x}$ & $\mathrm{x}$ & $\mathrm{x}$ \\
\hline $\begin{array}{l}2 \text { - Imagine this is your personal } \\
\text { page. How can you change your } \\
\text { profile info? }\end{array}$ & Edit profile & $\mathrm{x}$ & & $\mathrm{x}$ & & & & $\mathrm{x}$ & $\mathrm{x}$ \\
\hline $\begin{array}{l}3 \text { - Do you think there's new infor- } \\
\text { mation you haven't seen yet? } \\
\text { Where can you check? }\end{array}$ & Notifications & $\mathrm{x}$ & $\mathrm{x}$ & $\mathrm{x}$ & $\mathrm{x}$ & $\mathrm{x}$ & $\mathrm{x}$ & $\mathrm{x}$ & $\mathrm{x}$ \\
\hline $\begin{array}{l}4 \text { - Imagine you want to comment } \\
\text { on the second post. What should } \\
\text { you do? }\end{array}$ & Comment & $\mathrm{x}$ & $\mathrm{x}$ & $\mathrm{x}$ & $\mathrm{x}$ & $\mathrm{x}$ & $\mathrm{x}$ & $\mathrm{x}$ & $\mathrm{x}$ \\
\hline $\begin{array}{l}5 \text { - Now you want to add a photo } \\
\text { and insert a comment to share with } \\
\text { the group. }\end{array}$ & Write post & $\mathrm{x}$ & $\mathrm{x}$ & $\mathrm{x}$ & $\mathrm{x}$ & $\mathrm{x}$ & $\mathrm{x}$ & $\mathrm{x}$ & $\mathrm{x}$ \\
\hline $\begin{array}{l}6 \text { - Send a private message to the } \\
\text { educator. }\end{array}$ & $\begin{array}{l}\text { Send mes- } \\
\text { sages }\end{array}$ & $\mathrm{x}$ & $\mathrm{x}$ & $\mathrm{x}$ & $\mathrm{x}$ & $\mathrm{x}$ & $\mathrm{x}$ & $\mathrm{x}$ & $\mathrm{x}$ \\
\hline $\begin{array}{l}7 \text { - Do you have unread messages? } \\
\text { From who? }\end{array}$ & $\begin{array}{l}\text { Received } \\
\text { msg. }\end{array}$ & $\mathrm{x}$ & $\mathrm{x}$ & $\mathrm{x}$ & $\mathrm{x}$ & $\mathrm{x}$ & $\mathrm{x}$ & $\mathrm{x}$ & $\mathrm{x}$ \\
\hline
\end{tabular}




\begin{tabular}{|c|c|c|c|c|c|c|c|c|c|}
\hline $\begin{array}{l}8 \text { - Access the news from kinder- } \\
\text { garten. }\end{array}$ & News & $\mathrm{x}$ & $\mathrm{x}$ & $\mathrm{x}$ & & $\mathrm{x}$ & $\mathrm{x}$ & $\mathrm{x}$ & $\mathrm{x}$ \\
\hline 9 - Add the news to favorites. & Add favorites & $\mathrm{x}$ & $\mathrm{x}$ & $\mathrm{x}$ & $\mathrm{x}$ & $\mathrm{x}$ & $\mathrm{x}$ & $\mathrm{x}$ & $\mathrm{x}$ \\
\hline $\begin{array}{l}10 \text { - Access photos about outdoor } \\
\text { activities. }\end{array}$ & Gallery & $\mathrm{x}$ & $\mathrm{x}$ & $\mathrm{x}$ & $\mathrm{x}$ & $\mathrm{x}$ & & $\mathrm{x}$ & $\mathrm{x}$ \\
\hline $\begin{array}{l}11 \text { - Share with other parents a site } \\
\text { with funny activities. }\end{array}$ & $\begin{array}{l}\text { Educational } \\
\text { resources }\end{array}$ & & & & & & & & \\
\hline $\begin{array}{l}12 \text { - Check for interesting book } \\
\text { suggestions to read. }\end{array}$ & Suggestions & & & & & & & & $\mathrm{x}$ \\
\hline $\begin{array}{l}13 \text { - Share, with the other parents, } \\
\text { information about a play that will } \\
\text { happen at the Congress Centre. }\end{array}$ & Agendinha & $\mathrm{x}$ & $\mathrm{x}$ & $\mathrm{x}$ & $\mathrm{x}$ & $\mathrm{x}$ & $\mathrm{x}$ & $\mathrm{x}$ & \\
\hline $\begin{array}{l}14 \text { - Check the date of Kindergar- } \\
\text { ten's party. }\end{array}$ & Events & $\mathrm{X}$ & $\mathrm{x}$ & $\mathrm{x}$ & $\mathrm{x}$ & $\mathrm{x}$ & $\mathrm{x}$ & $\mathrm{x}$ & $\mathrm{x}$ \\
\hline $\begin{array}{l}15 \text { - Check the menu and weekly } \\
\text { activity plan of the kindergarten } \\
\text { classroom. }\end{array}$ & Information & $\mathrm{x}$ & & & & & & & $\bar{x}$ \\
\hline $\begin{array}{l}16 \text { - Open the rules of kindergar- } \\
\text { ten to check the periods in which } \\
\text { it closes. }\end{array}$ & $\begin{array}{l}\text { Documenta- } \\
\text { tion }\end{array}$ & $\mathrm{x}$ & $\mathrm{x}$ & $\mathrm{x}$ & $\mathrm{x}$ & $\mathrm{x}$ & $\mathrm{x}$ & $\mathrm{x}$ & $\bar{x}$ \\
\hline $\begin{array}{l}17 \text { - See the profile of the mother } \\
\text { Anna. }\end{array}$ & Members & $\mathrm{x}$ & $\mathrm{x}$ & $\mathrm{x}$ & $\mathrm{x}$ & $\mathrm{x}$ & $\mathrm{x}$ & $\mathrm{x}$ & $\mathrm{x}$ \\
\hline $\begin{array}{l}18 \text { - You want to do an educational } \\
\text { activity with your child/class. } \\
\text { Show some contents you've } \\
\text { saved. }\end{array}$ & See favorites & $\mathrm{x}$ & $\mathrm{x}$ & $\mathrm{x}$ & & & & & $\mathrm{x}$ \\
\hline $\begin{array}{l}19 \text { - See information the educator } \\
\text { shared with you about your child's } \\
\text { development. }\end{array}$ & $\begin{array}{l}\text { Child's his- } \\
\text { tory }\end{array}$ & $\mathrm{x}$ & $\mathrm{x}$ & $\mathrm{x}$ & $\mathrm{x}$ & $\mathrm{x}$ & $\mathrm{x}$ & $\mathrm{x}$ & $\mathrm{x}$ \\
\hline
\end{tabular}

Analyzing the table, tasks that caused major problems are associated with the areas: edit profile, educational resources, activities, information, and favorites. Participants' comments were considered for revision of the prototype in the second cycle of development. In task two, E1 said that "Edit profile" should be written next to the photo. Three parents said there should be a button in the personal area to edit the profile. In task four, P4 pointed out that a submit button is missing. He asked if he should just press the ENTER key. In task six, E4 found an error. The structure did not have a back button. Without it, he gets stuck in private messages. He also suggested that it should be possible to send private messages to multiple members at the same time. In task eight, E4 didn't identify the news because he was looking for a button named news. Task 11 was not achieved by any participant due to the nomenclature educational resources. Four participants suggested changing the name to links, useful links, or interesting links. Likewise, in task 12, none of the participants understood what were suggestions of activities, confusing the purpose of this area (sharing stories, songs, arts and crafts...), with educational resources (links to websites, apps, videos) and activities done in the kindergarten classroom. E1 said she did not agree on the division by typology, because the activities they do aren't confined (a book becomes a theatre, a song, a drawing), so they shouldn't be labeled in one category inside the platform. E3 has proposed taking out the word Suggestions because what makes sense is to share activities that 
they are doing at school or at home. P3 has identified another error: a link to return to homepage is missing. Task 13 was well understood, although P4 confused agendinha with events. Three participants considered that agendinha and events could be together. Two educators did not like the term agendinha (little agenda), it should be agenda, because they don't like to infantilize the language with children. E1 thinks that, like in resources and activities, it shouldn't be divided into categories, because it is one more step. She thinks it is simpler, just entering the event and describe what it is. Task 15 caused errors and several considerations. Three participants feel that there is no distinction between documentation and information. Three participants see no advantage in having this area, as information can be published in activities or news. E2 thinks information should disappear and be replaced by two new buttons, one for menus and another for planning. Educators and parents agree that menus are important to get parents to consult the platform. Task 18 also caused some errors. Participants were not considering favorites as a tool to save posts (links, events, photos) to show to their children, but for their own use. However, once they understood it, the possibility was very well accepted.

Final Interview. Finally, an interview was made to understand the attitude towards the platform, perceive interest and expectation of use by the participants, either parents or educators. Everyone considered the platform intuitive, easy to learn and use. Three participants mentioned that the kind of interaction is familiar. All educators said they will use the tool to communicate with parents privately and share information with everyone. All parents said they will use the platform to communicate with the educator, but only two considered sharing information with other parents. All educators think they will use the platform to develop learning activities with children in the classroom. Regarding parents, two of them said they will use it to do activities with their child. P2 said it depends on available content and P3 said she does not know, due to lack of time. Regarding the frequency of consultation and participation in the platform, responses varied, with educators tending to consider daily use and parents considering weekly use. Two participants mentioned that they will probably use the platform more if they can access it by a mobile phone.

\subsection{Evaluation moment - end of first cycle of development}

The evaluation with users of the paper prototype served to ascertain the relevance of the content, platform consistency and expected practicality, helping to predict the use of the platform by educators and parents. It allowed the research team to check the overall understanding of the platform by both profiles and to identify some improvements and changes to the initial prototype. It also allowed to identify attitudes towards the use of the platform.

Thus, regarding the performance of the users, most of the functionalities were well identified. There were mistakes and doubts that happened, recurrently, in same tasks: Change Profile, Educational Resources, Suggestions, Information and Favorites. Some navigation failures were identified, such as lack of back button. From this evaluation, it was decided to proceed with some changes: Add new buttons - edit profile, return to homepage, send comments, back in private messages; Rename 'Educational resources' 
to 'Educational links'; Remove Information area and create Menu area; Writing area will have no tabs; Join Events and Agenda, instead of being a calendar, it will be a chronology of posts where, both parents and educators, can post events of general interest or events related to kindergarten; Activities will be an area to share comments and photos about classroom projects; Educational Links, Activities and Agenda will not have subdivisions, since it is an extra step and it is not valued.

Regarding the user's attitude toward the platform, answers to the interview indicate that users value the platform and intend to use it. Educators want to have an active role, with a daily use for sharing photographs and comments on the activities they do with the children, while parents point to a weekly use, more directed towards communicating with the educator than for sharing with other parents or carrying out educational activities with children. Access through mobile devices seems to be a condition for more frequent use.

To conclude, tests on the paper prototype have identified small changes that could also be implemented at a later stage of development, such as back buttons or nomenclature. However, this evaluation led to rethinking areas of the platform that would be difficult to change later, due to complexity, development time and costs. As these changes were identified at this stage, they will optimize the programming work of the functional prototype and allow the inclusion of functionalities according to user's suggestions, such as: join agenda and events, writing area without tabs; Links and activities chronologically available, without subdivisions. This evaluation ended the first cycle of development, with important information to be included in the planning of the next development tasks.

\section{Second cycle of development}

\subsection{Programming the functional prototype}

The Second Cycle of Development took place between July and December 2016. Between July and September, the functional prototype was programmed. In October, the platform began to be used in kindergarten rooms for testing and improvement. The research team wanted to launch the functional prototype (Figure 3 ) on the $15^{\text {th }}$ September, to present it to parents and educators at the beginning of the school year at kindergartens. Having a small team and short development time, it was necessary to define priorities and choose the features to develop for the launch. 


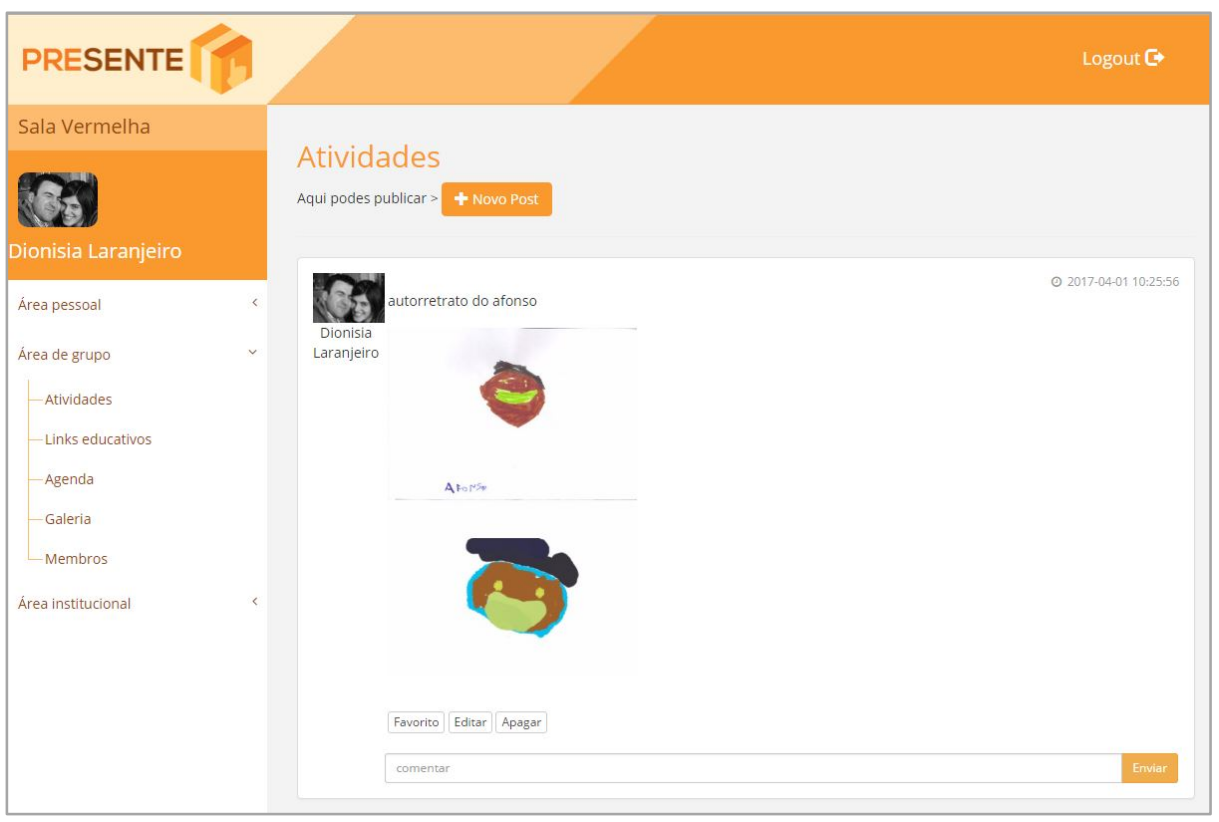

Fig. 3. Functional Prototype

Thus, it was decided to have a version that included a Backoffice, for the creation of virtual groups and users, and a Frontoffice, with selected functionalities that could promote more participation of users. In Backoffice, it was developed: a managing system of private groups, to list, create, edit and delete virtual rooms for kindergartens; a managing system for users, to list, create, edit and delete users, associate profile (educator or parent) and associate group. Since the platform contains personal data of children, users only access the information of the classroom attended by their children, with their login identification. At Frontoffice, it was privileged the development of the following functionalities: (i) Personal area - Child's history, to share private information between parents and educators; Favorites, to save posts of greater interest; Notifications, to inform when there is new information and encourage the consultation of information; Profile, to edit personal information, change password and profile image. (ii) Group area - sharing activities, allowing the inclusion of text and image in the post, events, allowing the inclusion of date, place and extra information, and educational links, allowing the introduction of weblinks, description and title. All members of the room can participate and see the posts in the group area. (iii) Kindergarten - news, area where the educator can share news from kindergarten with parents of the group. Other functionalities and system security measures will be implemented at the third cycle of development.

\subsection{The start of the Pilot Project}

The pilot project started in two kindergarten rooms (K1 and K2), with presentation of the platform in the start-up meetings of the school year. The third kindergarten room 
(K3) started later, in an interim meeting, in November. The participants of the fourth Kindergarten room withdrew from the project because the educator went on maternity leave and the substitute did not adhere.

The three kindergarten rooms had different positions regarding the use of technologies for PI. The educator from K1 had little experience, just using e-mail punctually. She felt outdated about technologies and valued the personal contact with the parents, to exchange information. However, parents had already requested the use of digital media to follow the work done in kindergarten. In K2, it was a common practice to use digital media to engage parents. Parents and educator used Messenger ${ }^{\circledR}$ for daily messages (e.g. remember to give a medication, bring something to school), private group of Facebook ${ }^{\circledR}$ (to share activities of the room or visits abroad), file sharing in the Cloud (sending photos every month) and even Skype ${ }^{\circledR}$ for videoconferences home-kindergarten. In K3, the educator used to create a bimonthly e-newsletter, in HTML, that she published online and then sent the link to parents. In the e-newsletter, she used to share photos and activities done in kindergarten, educational suggestions and other interesting subjects. Parents liked to receive the newsletter, however, it was a task that occupied the educator a lot of time.

In the presentation meetings, all functionalities of the platform were demonstrated and explained. Parents didn't express doubts and confirmed they understood the structure, navigation and functionalities. In K2, one parent said she understood but she needed to try at home, and maybe then she could have new doubts. Another parent agreed. The researcher encouraged parents to contact her by e-mail, to clarify doubts, report errors or give suggestions, that may promote the improvement of the platform. In K1, parents asked about safety measures. They wanted to know who could access the information about the classroom, showing concern about sharing pictures or personal information of their child's development. This was a recurrent theme in K3. A parent, that was a computer security expert, pointed to a series of measures needed to ensure information security. At the end, they signed an informed consent and gave their e-mail address. The intention was to collect parents' and educators' e-mails, to create virtual rooms and logins for all users, so that they had the opportunity to use the platform during one school year.

To create user accounts at the Platform Backoffice, the administrator only needs a valid e-mail, the profile of the user (educator or parent) and the kindergarten room to associate the user. A hidden password is automatically created and the login information is sent to the e-mail associated to the account.

Virtual rooms for K1 (with 23 users) and K2 (with 23 users) were created in October and started being used by parents and educators of both kindergartens. The research team could monitor the use of the platform through a web statistic program, observation of content posted by users on the platform, contact with the educators (emails, phone calls and meetings) and parents (e-mails).

\subsection{Data collection for Platform improvement}

The collected data refers to the period between October and December 2016, ending the Second Cycle of development. 
Web Statistics of the Platform. Statistical data on the number of hits, visits and page views per month were collected through Webalizer, a program provided by the hosting service. The following table shows the evolution of accesses during the first three months of use.

Table 2. Web Statistics from October 2016 to December 2016

\begin{tabular}{|c|c|c|c|c|c|c|}
\hline \multirow{2}{*}{ Month } & \multicolumn{3}{|c|}{ Daily average } & \multicolumn{3}{c|}{ Monthly totals } \\
\cline { 2 - 7 } & Hits & Pages & Visits & Hits & Pages & Visits \\
\hline Oct & 112 & 50 & 9 & 3473 & 1558 & 286 \\
\hline Nov & 278 & 86 & 16 & 8348 & 2603 & 487 \\
\hline Dec & 72 & 26 & 10 & 2254 & 817 & 320 \\
\hline & $\mathbf{1 5 4}$ & $\mathbf{5 4}$ & $\mathbf{1 1 , 6}$ & $\mathbf{1 4 0 7 5}$ & $\mathbf{4 9 7 8}$ & $\mathbf{1 0 9 3}$ \\
\hline
\end{tabular}

Considering that the total number of users in this period was 46 ( 2 educators and 44 parents), it was verified that there was a high volume of visits to the platform during the first month (286 visits), having almost doubled in the second month (487 visits). In the third month, the values dropped (320 visits), but remained above the first month. Altogether, during the first three months of use, there were 1093 visits with 4978 page views and an average of 11.6 visits per day.

Content posted on the platform. Contrasting with good access numbers, the participation in the first three months was short. In K1, the educator shared six events (related to activities in the library, amusement parks, cinema, among others), six activities (three posts to encourage parents to participate, others to report on activities developed with children), one link to an article on education. Regarding the parents' participation in the platform, there was a parent who published two articles on education, in the links area. There was another parent who made a comment to wish the group members a good weekend. Without accessing the content of the personal area, it was possible to verify that there was one private message between a parent and the educator. In K2, the educator shared eight events (activities taking place in kindergarten, theatre, solidarity, etc.), one activity (English activity performed with children), and one link to a video with English music to teach the lyrics. In this case, the educator complemented the information transmitted in the activities, with links to explore at home. During this period, there was no participation of parents in the platform, in the areas of activities, links, events, comments or private messages. However, eight parents have changed their profile information (name, photo). No educator shared any news in the kindergarten area.

Contact with the educators. Both educators were disappointed with the lack of participation of the parents. But they were motivated by the high number of visits that the web statistics showed, which could mean that parents assumed a passive role, but they were accessing the platform to see the information. Both educators reported some errors and gave suggestions for the third cycle of development. The errors that the K1 educator identified were that she couldn't comment, edit or delete a post that she had already published. As suggestions for improvements, the educator thinks that events should have the possibility of adding images and should not be obligatory to fill date and time 
fields, as these are not always known with precision. She suggested that in the description field of the event, each user could fill in with the data they have. She asked if it was possible to share videos, either. It would be a good functionality for parents. She also suggested that the next functionalities to be developed should be sending of notifications by email and the implementation of galleries with pictures from children's projects, two triggers to promote parent's participation in the platform. K2 educator reported the same errors, but added a problem in inserting profile image. The platform sometimes failed to insert the image. When it did, the image was inserted upside down. Also, she couldn't add posts to favorites. She mentioned that some parents had not received the e-mail with the access data (login and password), so they did not use the platform. As suggestions for improvements, the educator considers it very important to receive notifications when there is new content in the platform and, also, the adaptation to the mobile phone, which at this stage was not yet fully developed.

Contact with the parents. During this period, the support had received three e-mail messages from parents reporting that they didn't receive the e-mail with access information to login in the platform. The access data was resent to these users. One parent sent an e-mail suggesting that navigation between menus and content should take fewer steps. For example, when he was in the group area and wanted to see news of the institution, he had to open the Kindergarten menu and choose the submenu news. He thinks the submenu structure should always be open, so that navigation becomes more immediate. Another parent requested a meeting to discuss the platform's security issues. He found two points to improve. The first is that the platform should be on an HTTPS secure domain so that if users are accessing through a public Wi-Fi network, the data is encrypted and is not easily intercepted by strangers. The second is that the platform shouldn't allow for infinite login attempts. After three attempts and errors, the platform should block that IP's access for 15 minutes.

\subsection{Evaluation moment - end of the Second Cycle of Development}

The use of the functional prototype in the Second Cycle of Development was intended to collect data for improvements and corrections to be included in the final version of the platform. The collected data allowed to understand the functionalities that should be implemented in the last development cycle and, at the same time, it gave an overview of the use by the educators and the parents. In terms of improvements to be implemented in the third development cycle, it is considered:

Correction of errors: fix the errors of edit, change and comment posts; correction of the problem of uploading the profile images (it is necessary to put a limit of $\mathrm{Kb}$ to upload the images); fix the Favourites feature.

Priority implementation of features in response to user suggestions: notifications, image gallery, recover password, improvements in events area.

Implementation of security measures: HTTPS and IP blocking for continued attempts to access.

Implementation of the remaining functionalities to complete the platform: private message and child's history, members' page, documentation and menus in kindergarten area. 
Regarding the use of the platform in this period, educators shared varied content (activities, links, events), however, with a small amount of posts. This may be due to the parents not giving feed-back or the platform still have some errors that make it difficult to use more frequently. Parents reported errors and submitted suggestions for improvements to the support e-mail. Web Statistics show that there was an average of 364 accesses per month to the platform, which suggests that parents accessed without participating. As an explanation, it may be due to the need to adapt to a new form of communication or because the parents take the platform as a unilateral means of communication, to receive information about what is going on in kindergarten, rather than to communicate with the educator or with other parents.

\section{Final Considerations}

The development of a platform for PI in kindergarten must consider the needs, motivations and expectations of parents and educators, both in planning, use and evaluation. In this sense, the research team involved, from the beginning, four kindergarten groups with four educators and 84 parents, who participated in the whole process. In preliminary studies, numerous possibilities of development were presented to parents and educators. Results of this stage helped define the functional specifications and the architecture diagram. This led to the creation of a paper prototype that was tested in the First Development Cycle, with parents and educators. Usability tests allowed to redirect, simplify, and even eliminate previously specified functionalities. In the Second Cycle of Development, the use of the platform by two groups allowed the identification of some errors and to understand the most important and prior functionalities, as well as the tendencies of use by educators and parents. Thus, parents take a passive role, based on viewing the content of the platform, while the educators share information, but are waiting for parents to respond.

These data will also be important for the third cycle of development, not only in the implementation of corrections, but also to find ways to stimulate and promote parental participation in the platform, so that communication flows both ways and can have more impact in the PI in children's learning process.

\section{Acknowledgements}

This article reports research developed within the PhD Program Technology Enhanced Learning and Societal Challenges, funded by Fundação para a Ciência e Tecnologia, FCT I. P. - Portugal, under contract \# PD/00173/2014. The first author has a grant from the Foundation for Science and Technology (FCT) and the European Social Fund (ESF) under the III Community Support Framework (SFRH/BDE/95701/2013). 


\section{References}

1. Laranjeiro D, Antunes MJ, Santos P (2016) Plataforma tecnológica para o envolvimento parental na aprendizagem das crianças que frequentam o jardimde-infância - Estudo exploratório sobre as necessidades dos pais. In: TIC Educ. 2016 - Digit. Technol. Futur. Sch. (Artigos selecionados). pp 366-386

2. Epstein J (1995) School/family/community partnerships. Phi Delta Kappan 76:701.

3. Hoover-Dempsey K, Sandler H (1997) Why do parents become involved in their chidren's education? Rev Educ Res 67:3-42.

4. Weiss H, Caspe M, Lopez ME (2006) Family Involvement In Early Childhood Education. Harvard Fam Res Proj 1:1-8.

5. Epstein JL (1995) School/family/community partnerships: Caring for the children we share. Phi delta kappan 76:701.

6. Harris A, Goodall J (2008) Do parents know they matter? Engaging all parents in learning. Educ Res 50:277-289. doi: 10.1080/00131880802309424

7. Henderson A, Berla N (1994) A new generation of evidence: The family is critical to student achievement. National Committee for Citizens in Education

8. Desforges C, Abouchaar A (2003) The impact of parental involvement, parental support and family education on pupil achievements and adjustment: A literature review. Nottingham

9. Melhuish EC, Phan MB, Sylva K, et al (2008) Effects of the home learning environment and preschool center experience upon literacy and numeracy development in early primary school. J Soc Issues 64:95-114.

10. Fan X, Chen M (2001) Parental involvement and students' academic achievement: A meta-analysis. Educ Psychol Rev 13:1-22.

11. Hilado A V., Kallemeyn L, Phillips L (2013) Examining Understandings of Parent Involvement in Early Childhood Programs. Early Child. Res. Pract. 15:

12. Diamond KE, Justice LM, Siegler RS, Snyder PA (2013) Synthesis of IES Research on Early Intervention and Early Childhood Education. doi: NCESR 2013-3001

13. Sonnenschein S, Stapleton LM, Metzger SR (2014) What Parents Know About How Well Their Children Are Doing in School. J Educ Res 107:152-162. doi: 10.1080/00220671.2013.788987

14. Lunts E (2003) Parental Involvement in Children's Education : Connecting Family and School by Using Telecommunication Technologies. Meridian A Middle Sch. Comput. Technol. J. 6:

15. Stevenson DL, Baker DP (1987) The Family-School Relation and the Child's School Performance. Child Dev 58:1348-1357.

16. Plowman L, Stevenson O, McPake J, et al (2011) Parents, pre-schoolers and learning with technology at home: some implications for policy. J Comput Assist Learn 27:361-371. doi: 10.1111/j.1365-2729.2011.00432.x

17. European Commission/EACEA/Eurydice/Eurostat (2014) Key Data on Early Childhood Education and Care in Europe. Luxenbourg

18. Downer J, Myers S (2010) Application of a Developmental/Ecological Model 
fo Family/School Partnerships. In: Routledge (ed) Handb. Sch. Partnersh. Taylor \& Francis, pp 3-29

19. Hornby G (2011) Education, Parental Involvement in Childhood- Building Effective School-Family Partinerships. doi: 10.1007/978-1-4419-8379-4

20. Silva IL, Marques L, Mata L, Rosa M (2016) Orientações Curriculares para a Educação Pré-Escolar. Ministério da Educação/Direção-Geral da Educação, Lisboa

21. Grant L (2009) Learning in Families : A review of research evidence and the current landscape of Learning in Families with digital technologies. Bristol

22. Izzo C V, Weissberg RP, Kasprow WJ, Fendrich M (1999) A longitudinal assessment of teacher perceptions of parent involvement in children's education and school performance. Am J Community Psychol 27:817-839. doi: 10.1023/A:1022262625984

23. Grant L (2011) “I"m a completely different person at home': using digital technologies to connect learning between home and school. J Comput Assist Learn 27:292-302. doi: 10.1111/j.1365-2729.2011.00433.x

24. Bouffard S (2008) Tapping Into Technology: The Role of the Internet in Family - School Communication. Fam Involv Res Proj 1-5.

25. Olmstead C (2013) Using Technology to Increase Parent Involvement in Schools. TechTrends 57:28-37. doi: 10.1007/s11528-013-0699-0

26. Blanchard J (1998) The FamilySchool Connection and Technology. In: Proc. Fam. Technol. Educ. Conf. Chicago, pp 235-245

27. Carlson C (2010) Future Directions in Family-School Partnerships. In: Christenson S, Reschly A (eds) Handb. Sch. Partnersh. Routledge, pp 407-419

28. The New Media Consortium (2014) Horizon Report Europe > 2014 Schools Edition.

29. van den Akker J, Gravemeijer K, McKenney S, Nieveen N (2006) Educational design research. Routledge, London

30. Coutinho CP (2006) Aspectos metodológicos da investigação em tecnologia educativa em Portugal (1985-2000). Para um balanço da Investig. em Educ. 1960 a 2005 Teor. e práticas actas do Colóquio da AFIRSE

31. van den Akker J (1999) Principles and Methods of Development Research. In: Science S, Dorrecht BM (eds) Des. Approaches Tools Educ. Train. pp 1-22

32. Reeves TC (2000) Enhancing the Worth of Instructional Technology Research through "Design Experiments" and Other Development Research Strategies. Annu. Meet. Am. Educ. Res. Assoc.

33. Nieveen N, Folmer E (2013) Formative evaluation in Educational Design Research. In: Educ. Des. Res. Enschede, pp 152-169

34. Richey RC, Klein JD, Nelson WA (2008) Developmental research: studies of instructional design and development. In: Handb. Res. Educ. Commun. Tecnol. pp 1099-1130

35. Plomp T (2013) Educational Design Research: An Introduction. In: Educ. Des. Res. Netherlands Institute for Curriculum Development, Enschede, pp 10-51

36. The Design-Based Research Collective (2003) Design-Based Research: An Emerging Paradigm for Educational Inquiry. Educ Res 32:5-8. 
37. Hong SB, Trepanier-Street M (2004) Technology: A Tool for Knowledge Construction in a Reggio Emilia Inspired Teacher Education Program. Early Child Educ J 32:87-94. doi: 10.1007/s10643-004-7971-z

38. Faria Á, Ramos A (2011) Redes sociais no jardim de infância para aprender e partilhar com a família e a comunidade. In: XI Congr. Int. Galego-Portugués Psicopedag. Universidade da Coruña, pp 3-13

39. Knauf H (2016) Interlaced social worlds : exploring the use of social media in the kindergarten the kindergarten. Early Years. doi: $10.1080 / 09575146.2016 .1147424$

40. Näsänen J, Oulasvirta A, Lehmuskallio A (2009) Mobile Media in the Social Fabric of a Kindergarten. In: Conf. Hum. Factors Comput. Syst. - Proc. pp 2167-2176

41. Laranjeiro D, Antunes MJ, Santos P (2017) Development of a multimedia platform for parental involvement in learning of children attending kindergarten - Preliminary Studies. In: INTED2017 Proc. Valencia, pp 31573166

42. Garrett JJ (2011) The Elements of User Experience : User-Centered Design for the Web and Beyond, Second Edition. Jesse James Garrett. doi: 10.1145/889692.889709

43. Laranjeiro D, Antunes MJ, Santos P (2017) Multimedia Platform Development for Parental Involvement in Learning of Children Attending Kindergarten Iterative Cicles of Development. In: CSEDU - 9th Int. Conf. Comput. Support. Educ. pp 208-219

44. ISO (1998) ISO 9241-11 Ergonomic requirements for office work with visual display terminals ( VDTs ) - Part 11 : Guidance on usability.

45. Berns T (2004) Usability and user-centred design, a necessity for efficient elearning! Int J od Comput Internet Manag 12:20-25.

46. Nielsen J (2003) Paper Prototyping: Getting User Data before you code. In: Nielsen Norman Gr. https://www.nngroup.com/articles/paper-prototyping/.

47. Rubin J, Chisnell D (2008) Handbook of Usability Testing, Second Edition: How to Plan, Design, and Conduct Effective Tests, 2nd editio. Wiley Publishing, Inc., Indianopolis

48. Nielsen J, Sova D (2003) 234 Tips and Tricks for Recruiting Users as Participants in Usability Studies. In: Nielsen Norman Gr. www.nngroup.com/reports/how-to-recruit-participants-usability-studies.

49. Wharton C, Rieman J, Lewis C, Polson P (1994) The Cognitive Walkthrough Method: A Practioner's Guide. Boulder, Colorado

50. Someren MW va., Barnard YF, Sandberg JAC (1994) The Think aloud methoda practical guide to modelling cognitive processes. 